\title{
Diferentes configurações familiares de candidatos à adoção: Implicações para os processos de habilitação
}

Patricia Santos da Silva. Universidade Federal do Rio Grande do Sul

Eduarda Xavier de Lima e Silva. Universidade Federal do Rio Grande do Sul

Rita de Cássia Sobreira Lopes. Universidade Federal do Rio Grande do Sul

Giana Bitencourt Frizzo. Universidade Federal do Rio Grande do Sul

\section{Resumo}

Novas formas de exercício da parentalidade gradativamente conquistam reconhecimento na sociedade e embora não seja uma prática recente, a adoção é vista mais frequentemente como opção às famílias. Assim, este estudo investigou a visão dos técnicos judiciários sobre a habilitação de novos perfis de candidatos e identificou diferenças nas avaliações. Foram entrevistados 17 psicólogos e assistentes sociais que realizavam avaliações de candidatos à adoção no sul do Brasil. A análise de conteúdo das entrevistas mostrou diferenças nas avaliações nos temas: divisão de papéis em casais homossexuais, rede de apoio em famílias monoparentais, projeto adotivo comum nos recasamentos e distanciamento geracional para os idosos. Percebeu-se preocupação com as crianças adotivas, mas alguns relatos retrataram valores ligados a concepções biológicas de família. Pensa-se que as várias configurações familiares apresentam desafios aos profissionais. Portanto, ressalta-se a importância de que os profissionais conheçam essas questões para combater preconceitos e reinventarem novos modos de atuação.

Palavras-chave: adoção; família; parentalidade.

\section{Abstract}

Different family configurations of adoption applicants: Implications for habilitation process. New forms of parenting are gradually becoming more recognized in the society and, although not a new practice, adoption is seen increasingly as an option for families. This study investigated the view of juridical technicians involved in the habilitation process of new profiles of adoption applicants and also identified differences within those evaluations. Seventeen psychologists and social workers in southern Brazil were interviewed. Qualitative content analysis showed differences in practices about the issues: role division in homosexual couples, support-network in monoparental families, adoption as a family project in remarriages and generational gap in older applicants. These themes reflected concern for the children placed in adoption, but some reports portray values connected to biological family conceptions'. The various families' possibilities present challenges to professionals. Therefore, it's important that professionals know those subjects to combat prejudices and reinvent new performance modes.

Keywords: adoption; family; parenting.

\section{Resumen}

Diferentes configuraciones familiares de candidatos a adopción: Implicaciones para los procesos de habilitación. Nuevas configuraciones del ejercicio de la parentalidad vienen conquistando gradualmente un mayor reconocimiento en la sociedad y aunque no sea una práctica nueva, la adopción se ve cada vez más como opción para formar una familia. Así, el presente estudio investigó el parecer de los técnicos judiciales sobre la habilitación de nuevos perfiles de candidatos e identificó diferencias en sus evaluaciones. Fueron entrevistados 17 psicólogos y asistentes sociales que realizaban evaluaciones de candidatos a adopción en el sur de Brasil. El contenido cualitativo de las entrevistas mostró diferencias en las prácticas en los temas: divisiones de papeles en parejas homosexuales, red de apoyo en familias monoparentales, proyecto adoptivo común en casos de segundas nupcias y distanciamiento generacional en candidatos mayores. Se realizó que estos temas reflejaron preocupación con los niños en adopción pero algunos relatos mostraron valores vinculados a concepciones biológicas de familia. Se observa que las varias posibilidades de familia presentan desafíos a los profesionales. Se debe resaltar, así, la importancia de que estos profesionales conozcan esa realidad para combatir y que repiensen nuevos modos de actuación. Palabras clave: adopción; familia; parentalidad. 
As inúmeras mudanças e transformações dos séculos XX e XXI produziram reflexos significativos nas relações familiares, propiciando o surgimento de novas configurações, bem como estão transformando as concepções de conjugalidade e parentalidade (Souza, Beleza, \& de Andrade, 2013). O conceito de família pode ser entendido como uma organização complexa que exerce influência sobre a constituição e a organização da personalidade de seus membros e sobre o comportamento do ser humano em sociedade (Pratta \& Santos, 2007). A estruturação da família está diretamente ligada ao contexto e determinada por variáveis ambientais, sociais, econômicas, culturais, religiosas e históricas (Osório, 1996). Em função disso, é considerada um sistema ativo em constante transformação que se modifica no decorrer do tempo para lidar com os diversos eventos com que se depara (Carter \& McGoldrick, 1995).

Desse modo, a família passa por transformações à medida que as sociedades vão se desenvolvendo e evoluindo. Os padrões de família e casamento mudaram muito no mundo ao longo do século XX e os tipos de família têm se tornado cada vez mais diferentes do modelo ocidental de família nuclear composta por "pai, mãe e filhos" (Giddens, 2009). Segundo o autor, em muitos países desenvolvidos, as relações de intimidade se tornaram mais abertas e menos presas às tradições, especialmente após 1960. Além disso, a combinação de um aumento das taxas de divórcios, recasamentos e de pessoas vivendo sozinhas parecem negar a ideia de uma convergência da estrutura familiar e isso vem acontecendo de maneira globalizada.

Essas mudanças vêm fazendo com que as teorias a respeito do desenvolvimento e do ciclo de vida familiar evoluam. Tendo isso em vista, Cerveny e Berthoud (2011) propuseram um novo modelo para compreender o ciclo de vida familiar que leva em consideração diferentes configurações familiares. Segundo as autoras, a chamada fase de aquisição, aquela em que a nova família está se constituindo e preocupada em adquirir estabilidade emocional e financeira, pode ser vivida pelos mais diversos padrões familiares, principalmente em relação à vivência da parentalidade. O objetivo hoje é construir uma vida que satisfaça os anseios de individualização preconizados pelos padrões sociais emergentes de felicidade e realização.

Esses anseios têm demonstrado uma exaltação de valores ligados à afirmação da individualidade em contraposição aos valores sociais, o que parece aumentar as tensões familiares, favorecendo a desintegração e fazendo com que o número de famílias monoparentais e reconstituídas seja cada vez maior (Andolfi, Angelo, \& Saccu, 1995). Somando-se a isso, novas tecnologias de reprodução e outras formas de exercício da parentalidade vêm permitindo que famílias lideradas por casais homoafetivos, e por somente uma das figuras parentais, ganhem cada vez mais espaço na sociedade atual (Claster \& Blair, 2013; Costa \& Marra, 2013; Pontes, Féres-Carneiro, \& Magalhães, 2015; Zambrano, 2006), dando espaço, inclusive, às pluriparentalidades que permitem que uma criança tenha mais de um pai ou mais de uma mãe (Uziel, 2000). Além disso, a sociedade contemporânea tem ampliado gradativamente o debate a respeito das questões que tratam da adoção, o que tem contribuído sistematicamente para a "normalização da família adotiva" (Schettini, Amazonas, \& Dias, 2006). Para os autores, se antes a adoção era entendida pela sociedade como um desvio do padrão biológico de constituição de um núcleo familiar, hoje é compreendida como uma forma válida de parentalidade e filiação, sendo uma possibilidade de construir vínculos baseados no afeto, para além dos vínculos consanguíneos.

Nesse sentido, em função das novas configurações familiares, a adoção, embora não seja uma prática recente, é vista cada vez mais frequentemente como uma opção, e não somente como uma alternativa à infertilidade (Böttger, 2007; Maux \& Dutra, 2010; Otuka, Scorsolini-Comin, \& Santos, 2009). Por isso, é importante que se reconheça o crescimento do número de famílias com novas configurações no cenário nacional.

Apesar das mudanças presentes nas organizações familiares modernas, os fatores a serem avaliados no processo de habilitação deveriam ser os mesmos, enfocando questões como história de vida, características pessoais, relacionamento familiar e social e, principalmente, a motivação (Silva, 2015). Hamad (2010) apontou que as candidaturas devem ser julgadas pelas "aptidões" dos candidatos de assumir uma criança e de lhe oferecer as condições necessárias ao seu pleno desenvolvimento. Nesse sentido, para os autores, o mais importante a ser considerado nas avaliações deveriam ser as condições psicossociais de cada candidato e não sua orientação sexual ou o estado civil, o que faz com que os técnicos judiciários se confrontem permanentemente com as questões das formas de famílias atuais.

A literatura é pouco profícua a respeito da habilitação de diferentes perfis de candidatos à adoção, o que pode trazer dificuldades à prática dos profissionais, visto que diferentes configurações familiares têm 
feito com que a busca pela adoção seja cada vez mais comum. Mesmo ainda sendo mais frequentes, casais inférteis não são os únicos a buscarem esta modalidade como uma maneira de realizarem seus desejos de serem pais e mães. Da mesma maneira que as famílias têm mudado ao longo do tempo, os candidatos à adoção podem representar essas mudanças. Nesse sentido, possivelmente os profissionais acabam por se deparar com outras questões que devem ser investigadas e refletidas nesse processo. Em função disso, o presente estudo teve como objetivo investigar a visão dos profissionais a respeito da habilitação de diferentes perfis de candidatos e identificar as implicações nessas avaliações.

\section{Método}

\section{Participantes}

Os participantes foram sete psicólogos e 10 assistentes sociais judiciários de sete cidades do estado do Rio Grande do Sul que trabalhavam nos Juizados da Infância e da Juventude nas avaliações de candidatos nos processos de habilitação para adoção. Os profissionais eram formados há um período médio de 24 anos $(D P=7,13)$ e trabalhavam no judiciário há uma média de 14 anos ( $D P=9,65)$, sendo o mínimo 4 meses e o máximo 28 anos de experiência no judiciário. As mulheres representaram $94 \%$ dos participantes. As entrevistas de todos os participantes recrutados foram utilizadas para análise posterior dos dados.

\section{Instrumentos}

Para o estudo, foram utilizadas duas entrevistas semiestruturadas elaboradas pelas autoras: Entrevista de Dados Profissionais e Entrevistas sobre os Processos de Habilitação para Adoção - versão psicólogos e versão assistentes sociais. A primeira abordou temas relacionados à formação profissional, o tempo de trabalho na comarca, os tipos de processos atendidos e ao incentivo à capacitação profissional percebido pelo participante. A segunda, temas referentes ao fluxo dos processos em cada comarca, participação dos profissionais nos processos, avaliação de candidatos à adoção conforme a especialidade profissional, critérios utilizados nas avaliações e preparação dos candidatos.

\section{Procedimentos}

Primeiramente, os profissionais foram contatados por e-mail a fim de se verificar o interesse e a disponibilidade em participar da pesquisa. Após esse primeiro contato, foi solicitada ao juiz da comarca uma autorização para a participação do profissional e, após, fez-se o agendamento das entrevistas nos locais de trabalho dos participantes. Os profissionais responderam a duas entrevistas, individualmente, após a assinatura do Termo de Consentimento Livre e Esclarecido.

As entrevistas foram gravadas em áudio digital e transcritas. Os dados provenientes foram analisados por meio da análise de conteúdo (Bardin, 2011; Laville \& Dione, 1999) e as categorias emergiram a partir da leitura dos dados. A análise foi realizada com o auxílio do software NVivo versão 10 (NVivo Qualitative Data Analysis Software - Version 10, 2012) na organização e categorização dos dados. Para o presente estudo, foram analisadas as respostas dos profissionais à pergunta "Sabendo-se que existem diferentes perfis de candidatos que buscam a adoção, existem peculiaridades na avaliação desses diferentes perfis?" da segunda entrevista. Optou-se por uma não distinção entre as falas de psicólogos e assistentes sociais por se perceber que os temas abordados eram comuns em diversos relatos, apesar da diferença profissional, e para preservar o sigilo em relação à identidade dos participantes.

\section{Resultados}

Quando questionados a respeito de peculiaridades no processo de avaliação conforme diferentes perfis de candidatos, os profissionais apontaram questões relevantes para a investigação. A motivação foi considerada pelos profissionais como o principal critério que deve ser utilizado nesses processos. No entanto, foi possível identificar que as práticas são diferenciadas de acordo com as características desses pretendentes que serão avaliados. Os profissionais citaram diferentes perfis como casais inférteis e casais com filhos biológicos. No entanto, no presente artigo, foram consideradas somente as novas configurações familiares que foram categorizadas em: Casais homoafetivos, Candidatos solteiros, Famílias reconstituídas e Candidatos idosos (Silva, 2015).

\section{Casais Homoafetivos}

Em relação à habilitação para adoção de casais homoafetivos, os profissionais relataram ter percebido que o processo passou por uma evolução em função das mudanças sociais hoje observadas. Alguns participantes falaram que sentem que hoje há uma naturalidade maior na habilitação desse perfil do que havia anos atrás. Segundo eles, com essa mudança, as questões investigadas são basicamente as mesmas de um casal 
heteroafetivo. Alguns profissionais falaram de maneira bastante positiva desses candidatos, dizendo que geralmente são pessoas mais flexíveis em relação ao perfil de criança desejado. Também mencionaram que tendem a ter um nível de maturidade maior nos relacionamentos quando chegam à decisão de adotar: "[...] até o momento eu não tive problemas em relação a essas questões de gênero, porque geralmente são pessoas que já tiveram toda uma elaboração, toda uma preparação pessoal, são pessoas mais trabalhadas". (P2) ${ }^{1}$

Apesar disso, os profissionais destacaram algumas peculiaridades na avaliação de casais do mesmo sexo. Na maioria dos relatos apresentados, foi possível perceber uma influência de um padrão tradicional de família, visto que muitos citaram casais heterossexuais como um modelo de avaliação. No relato que segue pode-se apreender a importância dos papéis tradicionais de gênero para a habilitação de casais homoafetivos:

Como é que eles vão fazer essa separação de papéis, do homem, da mulher, ou melhor, das duas mulheres ou dos dois homens? Porque eu acho que a criança precisa ter as duas coisas, [...] a questão mais do limite, a questão mais do afeto, se eles vão conseguir ter essas duas coisas bem fortes. (P10)

\section{Candidatos Solteiros}

Com os pretendentes solteiros que buscam a adoção, a principal questão apontada pelos profissionais foi em relação à rede de apoio com que essa pessoa pode contar: se a família extensa concorda e incentiva o projeto adotivo, se fornece uma referência a esse núcleo familiar que se formará. Caso não haja outros membros na família, pode-se investigar a presença de amigos ou outros círculos sociais que possam prover esse auxílio. Segundo um dos relatos, essas questões aparecem em função do bem-estar da criança: "[...] a gente tem que ter essa certeza de que a criança vai ficar bem. Vamos supor que aconteceu alguma coisa com ela (a candidata) - onde vai a criança?" (P3)

Além da questão da demanda de cuidado que a criança pode apresentar à família extensa, os profissionais referiram como importante perceber o quanto o candidato está se organizando para cuidar sozinho de um filho, se já refletiu sobre a disponibilidade que precisará ter para dedicar-lhe a atenção necessária: "Uma pessoa sozinha a gente averigua como é a condição do trabalho, como é que ela pensa nos primeiros meses, porque os primeiros tempos são mais importantes da criança." (P4)
O quanto o pretendente deseja um filho e não somente alguém para preencher um vazio, ou porque se sentem solitários, também pareceu importante de ser avaliado. Além disso, o motivo de estar solteiro também se mostrou relevante:

Muitas mulheres já nessa idade já fizeram suas carreiras profissionais [...] aí chegam por essa idade da vida e se sentem meio sem saber o que fazer. Então isso a gente tem que ter um pouco de atenção para ver se não é só um reforço de companhia, né? (P18)

\section{Famílias Reconstituídas}

Outra peculiaridade que parece ser relevante é a questão dos recasamentos. Segundo os participantes, é importante investigar se o desejo por um filho é mesmo um projeto conjunto, visto que em casos nos quais há diferença de idade entre os cônjuges, a adoção pode vir para satisfazer as necessidades de apenas um deles: "De casais que o cara já foi casado e a mulher já foi e um deles não teve filho - geralmente, a mulher. Só isso, para saber se a motivação é dos dois." (P3)

Outra questão importante, que se observou na fala de um dos participantes, foi em relação ao porquê de quererem tanto ter outro filho. Segundo o relato, existem alguns casos em que o casal não consegue nem mesmo suprir as necessidades dos filhos biológicos e buscam a adoção na tentativa de ter um filho deste novo relacionamento: "[...] Eles sempre querem um filho pra eles, né? Então também a gente tem que ter atenção. Por que motivos querem esse filho?" (P18)

\section{Candidatos Idosos}

Os casais idosos também foram mencionados pelos profissionais, como um novo desafio para os processos de habilitação à adoção. Segundo eles, se faz importante investigar a motivação para a adoção. Um dos profissionais fala do atual modo de vida, em especial, ao investimento no trabalho e às demandas profissionais que podem fazer com que os casais adotem mais tardiamente:

Mas, às vezes, quando os dois [são mais velhos], é porque [...] alguma coisa fez que eles não buscassem ter o filho antes. Então, a gente vai ver bem o que aconteceu [...] Muitos esperam fazer toda a faculdade, toda a pós, mestrado, doutorado, viajar o mundo inteiro... aí, quando vão ter filhos, não podem mais. (P7) 
Os profissionais também ressaltam a importância de trabalhar com esses candidatos as suas condições de auxiliar no desenvolvimento de um filho, nesse momento de vida, atendendo as suas necessidades mesmo com uma idade mais avançada. Nesse sentido, para além de confrontá-los com questões do ciclo vital, do distanciamento geracional, os profissionais fazem um exercício de pensar no perfil de criança que seria mais adequado para o casal conseguir dar conta:

Então, isso nos traz uma questão a mais, de poder pensar, além da idade, que outras questões podem vir a desfavorecer a inserção de uma criança nesse contexto. Claro que, sim, tu vais acabar assinalando a questão geracional, a questão do ciclo vital... Não deixo de mencionar essa questão. (P9)

A investigação da rede de apoio também foi citada por um profissional como ponto importante na avaliação, para que caso haja algum incidente com o casal - em virtude da própria idade, alguém possa assumir os cuidados desse filho: "[...] Porque, quando a idade é grande, a gente tem de ver, na família, quem seriam as pessoas mais próximas, caso eles venham a faltar. Eu tenho esse cuidado." (P6)

\section{Discussão}

A partir das vinhetas apresentadas, foi possível perceber que as novas configurações familiares trazem peculiaridades na prática dos profissionais nos processos de habilitação para adoção. A respeito da adoção por homossexuais, estudos vêm investigando cada vez mais essa questão, visto a evolução social que vem sendo observada. A questão da resiliência e maior capacidade de elaboração, que apareceu na fala de um dos profissionais, também aparece no estudo de Marvin e Miller (2002) que sugeriram que casais do mesmo sexo tendem a serem altamente coesivos, flexíveis e abertos a receber o apoio social. Autores como Richards, Jonathan e Kim (2015)partners reported that their relationship processes emerged based on a desire for mutuality and attunement. Socio-Emotional Relationship Therapy (SERT, que investigaram 40 casais do mesmo sexo, dentre eles 20 masculinos e 20 femininos, apontaram que casais homoafetivos tendem a dividir mais a responsabilidade da relação. Segundo eles, a igualdade entre os participantes é um reflexo da sintonia com as necessidades e interesses da cada um, e da atenção às estratégias de equidade no relacionamento.
A questão apontada pelos profissionais de que os casais homoafetivos tendem a ser mais abertos na escoIha do perfil da criança pode ser discutida à luz da literatura. Para Goldberg, Downing e Moyer (2012), casais gays que escolhem tornarem-se pais através da adoção, o fazem completamente fora de um modelo tradicional de família e têm um filho em um contexto relacional único já que nenhum dos pais é geneticamente relacionado a ele. Casais de lésbicas também mostraram não priorizar características genéticas, ao contrário de casais heterossexuais (Goldberg, Downing, \& Sauck, 2008) their explanations of why preferences for one parent existed (or not. O estudo de Raleigh (2012) mostrou que casais homoafetivos tendem a adotar mais crianças negras do que casais heteroafetivos. Tendo isso em vista, pode-se pensar que a escolha de casais homossexuais por crianças mais velhas ou de outra origem étnica faz mais sentido dentro desse contexto, já que a escolha pela adoção não se vê influenciada pelos padrões biológicos de parentalidade.

Apesar disso, sabe-se que casais homoafetivos ainda suscitam preconceitos que podem trazer dificuldades e encontram um desafio adicional na sua jornada em direção à parentalidade adotiva (Jennings, Mellish, Tasker, Lamb, \& Golombok, 2014). As autoras apontaram que casais homoafetivos precisam superar barreiras internalizadas e ajustar suas expectativas de vida familiar para que haja compatibilidade com seu próprio relacionamento. Nesse sentido, Marvin e Miller (2002) também acrescentam que as dificuldades de aceitação trazem um novo desafio à formação do casal e o enfrentamento dessas dificuldades pode fazer com que cheguem à adoção com questões mais elaboradas e pensadas. Por isso, segundo as autoras, a opção de ter um filho é, geralmente, mais madura e feita em uma etapa mais estável da vida. Alguns relatos apresentados neste estudo corroboram esses dados.

A respeito da adoção por solteiros, a literatura também enfatiza a importância da rede de apoio para estas famílias que se constituem. A presença de uma rede de apoio apareceu como fundamental para as famílias monoparentais adotantes investigadas por Santos, Fonsêca, Fonsêca e Dias (2011). Isso porque permite suprir a necessidade do outro na relação, ampliando as possibilidades de socialização e identificações do adotado. As autoras ainda enfatizaram o suporte psicológico, moral e material disponibilizado por familiares, amigos ou vizinhos, que irá auxiliar a criança a elaborar suas dúvidas e incertezas. Os próprios adotantes do 
estudo consideravam importante a aceitação da família, apesar de relatarem que não deixariam de adotar caso a família não concordasse.

A falta de uma das figuras parentais tradicionalmente observadas não é necessariamente um fator negativo para o desenvolvimento infantil. Biblarz e Stacey (2010) apontaram que mães heterossexuais solteiras apresentam diversos pontos fortes no exercício da parentalidade como supervisão dos filhos, envolvimento nos cuidados, participação na escola e cuidados com a saúde da criança, fazendo com que elas apresentem mais desfechos positivos nesses aspectos. Também Ribeiro, Silva e Cezar-Vaz (2012) encontraram que homens que criam os filhos sozinhos têm condições essenciais para o seu cuidado, apesar das dificuldades financeiras, emocionais e organizacionais que a monoparentalidade pode trazer. Essa questão também apareceu como relevante na fala dos profissionais quando referiram a necessidade de uma disponibilidade maior dos solteiros para as demandas da criança.

Outra questão que pode ser apontada em relação à monoparentalidade diz respeito ao risco de se estabelecer uma relação simbiótica em uma configuração familiar de duas pessoas. Minuchin e Fishman (1990) chamaram essa configuração específica de famílias pas de deux. Para os autores, qualquer configuração familiar, não importa o quão viável possa ser, apresenta áreas de possíveis dificuldades ou elos fracos na corrente. Nessa configuração de duas pessoas, o risco é de que a união excessiva acabe cerceando o potencial de funcionamento de cada membro. Também por isso pode ser importante o que foi referido pelos profissionais sobre investigar se o filho não é desejado apenas para suprir um vazio pessoal. No entanto, essa questão também pode ser discutida, já que esse sentimento de vazio pode estar presente em casais em consequência de problemas na conjugalidade e não somente em função de não estarem em um relacionamento afetivo.

Em relação às famílias reconstituídas, foi possível observar a importância de se investigar se o projeto adotivo do casal é comum aos dois. Em relação a isso, a literatura aponta que em qualquer configuração de casal e de filiação, o projeto, para ser bem sucedido, deve ser de ambos os cônjuges (Hamad, 2002; Paiva, 2004). Nesse sentido, pode-se discutir a ênfase atribuída pelos profissionais a essa questão somente nos recasamentos, já que é uma questão que deveria ser primordial na avaliação de qualquer casal (Hamad, 2002; Nabinger, 2010).
Além disso, a questão referida por um dos participantes a respeito do desejo por um filho nesse novo relacionamento mostrou-se uma questão relevante. Nesse sentido, pode-se discutir a partir dos dados apresentados por Marcondes (2008). Ao analisar as trajetórias familiares de homens recasados, a autora verificou que as famílias estudadas tendiam a seguir a lógica de ter um filho em cada relacionamento, como algo que o consolidaria, principalmente nas famílias em que a nova esposa não tinha filhos de relacionamentos anteriores. Entretanto, questiona-se justamente a necessidade de um novo membro para consolidação desse novo núcleo familiar. Isso porque, hoje, o "ter um filho" é cada vez mais uma opção e não, exclusivamente, uma necessidade, na medida em que sexualidade e procriação não são mais indissociáveis (Rios \& Gomes, 2009). Ainda, os autores, ao analisar o funcionamento de casais que optaram por não ter filhos, discutem o estigma relacionado a esta "escolha". Nesse sentido, pode-se pensar que a ideia do filho como algo que "consolidaria" o relacionamento, pode estar ligada à cobrança social sofrida pelos casais em relação à necessidade de serem pais.

Considerando-se a adoção por candidatos idosos, percebe-se uma lacuna na literatura com relação a esse perfil específico de adotantes. Uma hipótese para tal questão pode ser o pouco acesso desses candidatos aos serviços de adoção, como ressaltado no estudo de Fonseca (2006). Neste trabalho, a autora analisou a circulação de crianças, em bairros populares de Cidade de Porto Alegre, pela chamada "adoção à brasileira" sem os devidos procedimentos legais. Fonseca (2006) salientou existirem diversos adotantes em potencial, como é o caso dos idosos, que não se sentiriam à vontade frente à burocracia dos serviços públicos. Esses candidatos não buscariam adotar uma criança legalmente em função do medo de um julgamento externo e de não atingirem certo padrão de "bons pais" estipulados pelos serviços de adoção, assim como casais mais pobres e sem união estável.

Além disso, a questão enfocada por um dos profissionais com relação ao adiamento da adoção em função dos candidatos priorizarem demandas profissionais é corroborado pela literatura. Andrade, Costa e RossettiFerreira (2006) investigaram as significações da paternidade no processo de adoção de um bebê e perceberam, através de seus casos, a influência de uma preocupação com a estabilidade financeira e emocional antes da chegada de um filho. As autoras sinalizam esse adiamento da adoção em função de um discurso emergente na classe média de preparação dos pais para esse momento. No 
entanto, pode-se pensar que tal questão não se restringe aos pais adotivos, na medida em que esse discurso permeia modelos contemporâneos de se pensar a parentalidade e passa a ser uma tendência atual os casais terem filhos cada vez mais tarde (Matos \& Magalhães, 2014).

A respeito de trabalhar as questões do ciclo vital e do perfil da criança com esses candidatos, de forma com que eles consigam exercer mais efetivamente a parentalidade, como mencionado pelos profissionais, a literatura também é pouco profícua. Ferreira (2001) fala que, no caso de adotantes idosos, em função de não haver uma limitação máxima de idade, esse por si só não seria um impedimento para a habilitação. $O$ autor ainda aponta a conformidade entre família adotiva e família biológica, tendo em vista as funções geracionais, pela própria lei delimitar uma diferença mínima de 16 anos entre adotante e adotado. Nesse sentido, a adoção tardia seria mais interessante para esse perfil de candidatos na tentativa de se evitarem problemas futuros em relação aos conflitos geracionais.

Apesar de muitos dados apresentados serem corroborados pela literatura específica como questões importantes de serem consideradas nos processos de habilitação para adoção, foi possível perceber, em alguns relatos dos profissionais, valores ainda muito relacionados a concepções biológicas de família. A partir disso é possível depreender que as várias possibilidades de configurações familiares vêm apresentando desafios aos profissionais que se veem frente à avaliação de diferentes perfis de candidatos. Aqueles que trabalham há mais tempo no judiciário referiram, inclusive, perceber tais mudanças.

Sobre isso se pode pensar que todos os tipos de família estabelecem vantagens e riscos para o desenvolvimento dos filhos, não se podendo afirmar, a priori, se há um tipo melhor do que outro. Casais heterossexuais fornecem uma legitimidade social e certo privilégio, já que são consideradas famílias mais "comuns" do ponto de vista social, porém são mais frequentemente associados a um menor grau de envolvimento de um dos membros da família (Biblarz \& Stacey, 2010), quando pai e mãe não dividem o cuidado com a criança.

Em uma revisão sistemática da literatura nacional buscando estudos que abordassem o tema da homoparentalidade, Cecílio, Scorsolini-Comin e Santos (2013) demonstraram que o tema ainda é permeado por controvérsias. Os autores referiram que a adoção por esses casais ainda é muito estigmatizada e alvo de preconceitos em função de questões religiosas, psicológicas, morais, sociais e jurídicas. Os estudos encontrados por eles, apenas 10 dentre os anos de 2000 a 2010, mencionaram os entraves impostos pela busca da legitimação da adoção por esses casais, entre eles o pressuposto de que os filhos adotivos sofreriam prejuízos na construção de suas identidades, ocasionando possíveis desvios de personalidade pela falta de referência do sexo oposto, sem contar as discriminações e preconceitos aos quais eles estariam expostos, o que apareceu muito na fala dos entrevistados.

Cabe discutir que pautar a avaliação a partir do que seria considerado "normal" numa família heterossexual, especialmente quanto à divisão de papéis, talvez não seja o melhor indicador a ser considerado nesses processos. Isso porque os papéis de homens e mulheres, bem como a divisão de tarefas nas famílias, podem não estar tão rigidamente estabelecidos e, ainda, vêm mudando com a evolução familiar (Carter \& McGoldrick, 1995; Wagner \& Levandowski, 2008).

Também a monoparentalidade ainda suscita questionamentos quanto ao desenvolvimento dos filhos e o bem-estar dos pais. Apesar disso, Stavrova e Fetchenhauer (2015), em um estudo que teve como objetivo comparar o bem-estar de pais solteiros e casados em 43 países europeus, observaram que os pais de famílias monoparentais apresentaram menores níveis de bem-estar que os casados somente em lugares onde, culturalmente, a monoparentalidade não é tão aceita na sociedade. Com isso, sugeriram a importância das normas culturais, principalmente as que dizem respeito ao individualismo e ao coletivismo, para o bem-estar e para o sentimento de felicidade das famílias.

O tema do preconceito é muito recorrente na literatura sobre adoção e apareceu em vários relatos dos profissionais entrevistados, principalmente em relação às suas concepções de família, sempre comparando com o modelo biológico. Santos et al. (2011) observaram que, em situações de adoção monoparental e tardia, o peso do preconceito apareceu como algo importante, principalmente em relação à aceitação do sistema familiar. Um dos participantes desse estudo, inclusive, enfatizou a necessidade de que a sociedade esteja mais preparada para lidar com as diversas possibilidades de se constituir família. Observa-se, ainda, que a postura omissa dos legisladores brasileiros em reconhecer e possibilitar a oficialização de novas configurações familiares, sobretudo daquelas protagonizadas por homossexuais (Camargo, 2012) dificulta a aceitação social dessas famílias.

Por fim, a questão do preconceito também pode ser questionada a partir do ponto de vista político-social e das implicações dele no poder legislativo brasileiro. 
Um exemplo disso é o projeto de lei trazido por $\mathrm{C}$. Almeida (2011) que prevê o dobro na dedução fiscal de dependentes adotados desde que sejam portadores de deficiência, de alguma doença grave ou afrodescendentes. Nesse sentido, Rodrigues e Hennigen (2014) questionam a ideia promovida da adoção como "salvação" a partir de incentivos financeiros.

\section{Considerações finais}

O presente estudo teve como objetivo investigar a visão dos profissionais a respeito da habilitação de diferentes perfis de candidatos e identificar se existem peculiaridades nessas avaliações. Foi possível observar que os participantes relataram peculiaridades nas avaliações, conforme os perfis questionados e que as questões abordadas refletiram a preocupação com a criança que poderá ser adotada por estes pretendentes. Dentre essas peculiaridades foi possível observar a questão da divisão de papéis, nos casos de famílias homoafetivas, da possibilidade de suporte por uma rede de apoio, nas famílias monoparentais, da importância de o projeto adotivo ser compartilhado pelos cônjuges nas famílias reconstituídas e as questões inerentes ao ciclo vital, nos casos de candidatos idosos.

Em relação a isso, foi possível discutir o preconceito a que todos estão sujeitos e que, por vezes, pode influenciar a prática profissional se não houver um questionamento sobre isso, devendo os técnicos se perguntarem se realmente estão preparados e livres de estigmas para lidar com as questões demandadas por essas novas configurações familiares (M. R. Almeida, 2008). Nesse sentido, faz-se importante ressaltar a importância de que os profissionais tenham em mente essas questões para combater seus próprios preconceitos ainda muito disseminados nas suas práticas, como pode ser inferido em alguns relatos do presente estudo. Além do que, se faz importante que os profissionais não pautem suas práticas em um padrão do passado, na medida em que esses padrões antigos acabam por não validar as mudanças observadas no presente (Carter \& McGoldrick, 1995).

Além disso, a parentalidade deve ser compreendida como um fenômeno social, inserida em um tempo e um espaço específicos (Berthoud, 2003) e, em relação a isso, percebe-se a importância da validação social das mudanças contemporâneas do ciclo vital (Carter \& McGoldrick, 1995). Isso, segundo as autoras, para que se possa questionar a respeito da ideia da família nuclear como sendo normal, visto que essa concepção de normalidade pode trazer sofrimento intenso às famílias que não se enquadram no perfil esperado socialmente, o que no caso da adoção, pode ser mais um complicador. Essa discussão vai ao encontro do que foi tratado por Schettini et al. (2006) quando apontaram a possibilidade de uma "normalização da família adotiva", que consolidaria a emergência de uma nova cultura de adoção.

Tendo em vista tais questões, entende-se que o trabalho dos profissionais do Judiciário passa por um momento de reflexão sobre a família contemporânea, sobre as mudanças ocorridas no âmbito da Justiça, sobre a necessidade de dispor de meios para melhor conhecer os candidatos à adoção, e, também, sobre seus próprios valores decorrentes de modelos internalizados de família (Zanetti, Oliveira, \& Gomes, 2013). Pode-se pensar que na medida em que a sociedade puder rever seus conceitos de família, a adoção tenderá a ser favorecida, propiciando mais oportunidades de adoção de crianças mais velhas, de etnias diferentes ou com alguma deficiência. Além do mais, pensando que o processo de habilitação para adoção se configura como um espaço de reflexão e preparação desses candidatos, é fundamental que os profissionais estejam abertos às novas possibilidades de família que possam surgir em benefício das crianças que serão colocadas em adoção.

Sabe-se, também, que este estudo não encerra as discussões a respeito do tema e que não aborda todas as possibilidades de configurações familiares com que se deparam os técnicos judiciários nos processos de habilitação para adoção. Além disso, reconhece-se a necessidade de se investigar outras realidades que não somente a do estado do Rio Grande do Sul a fim de gerar subsídios para um maior entendimento acerca da prática dos profissionais em nível nacional. Apesar disso, pode contribuir para um maior questionamento acerca dessa complexidade "dar voz" a esses profissionais que por vezes se veem solitários em suas comarcas. Ainda, espera-se que o presente estudo possa ter contribuído para trazer à tona questões que merecem mais atenção do ponto de vista acadêmico-científico,

\section{Referências}

Almeida, C. Projeto de Lei n. 942, de 2011 (2011). Recuperado de http://www.camara.gov.br/proposicoesWeb/ prop_mostrarintegra?codteor $=856889$ \&filename $=P L+942 / 2011$

Almeida, M. R. (2008). A adoção por homossexuais: um caminho para o exercício da parentalidade. Brasília: Conselho Federal de Psicologia. 
Diferentes configurações familiares de candidatos à adoção: Implicações para os processos de habilitação

Andolfi, M., Angelo, C., \& Saccu, C. (Orgs.). (1995). Parte IV: casais desintegrados e reconstituídos ( $3^{\mathrm{a}}$ ed., pp. 179-181). São Paulo: Summus.

Andrade, R. P., Costa, N. R. A., \& Rossetti-Ferreira, M. C. (2006). Significações de paternidade adotiva: um estudo de caso. Paidéia (Ribeirão Preto), 16(34), 241-252. doi: 10.1590/ S0103-863X2006000200012

Bardin, L. (2011). Análise de conteúdo. Lisboa: Edições70.

Berthoud, C. M. E. (2003). Re-significando a parentalidade: os desafios de ser pais na atualidade. Taubaté: Cabral Editora Universitária.

Biblarz, T. J., \& Stacey, J. (2010). How does the gender of parents matter? Journal of Marriage and Family, 72(1), 3-22. doi: 10.1111/j.1741-3737.2009.00678.x

Böttger, H. (2007). Mitos, prejuicios y discriminación: la supremacía de lo biologico: estado de la adopción en Chile. Cuadernos de Neuropsicología, 1(3), 236-244. http:// pepsic.bvsalud.org/scielo.php?script $=$ sci_arttext\&pi$\mathrm{d}=$ S0718-41232007000300006\&lng=pt\&tlng=es

Camargo, M. L. (2012). Adoção: vivências de parentalidade e filiação de adultos adotados. Curitiba: Juruá.

Carter, B., \& McGoldrick, M. (1995). As mudanças no ciclo de vida familiar: uma estrutura para a terapia familiar. Porto Alegre: Artmed Editora.

Cecílio, M. S., Scorsolini-Comin, F., \& Santos, M. A. (2013). Produção científica sobre adoção por casais homossexuais no contexto brasileiro. Estudos de Psicologia, 18(3), 507-516. doi: 10.1590/ S1413-294X2013000300011

Cerveny, C. M. O., \& Berthoud, C. M. E. (2011). Visitando a família ao longo do ciclo vital. São Paulo: Casa do Psicólogo.

Claster, P. N., \& Blair, S. L. (Orgs.). (2013). Visions of the 21st century family: transforming structures and identities (Vol. 7, p. iii). Emerald Group Publishing Limited. Recuperado de http://www.emeraldinsight.com/doi/abs/10.1108/S1530-3535(2013)0000007021

Costa, F. A. O., \& Marra, M. M. (2013). Famílias brasileiras chefiadas por mulheres pobres e monoparentalidade feminina: risco e proteção. Revista Brasileira de Psicodrama, 21(1), 141-153. Recuperado de http://pepsic.bvsalud.org/scielo.php?script=sci_abstract\&pi$d=$ S0104-53932013000100011\&lng=pt\&nrm=iso\&tlng=pt

Ferreira, L. A. M. (2001). Aspectos jurídicos da intervenção social e psicológica no processo de adoção. Serviço Social Em Revista, 5(1). Recuperado de http://www.uel.br/revistas/ssrevista/c_v5n1_Ferreira.htm

Fonseca, C. (2006). Da circulação de crianças à adoção internacional: questões de pertencimento e posse. Cadernos Pagu, (26), 11-43. doi: 10.1590/S0104-83332006000100002

Giddens, A. (2009). Sociology (6 $6^{\underline{a}}$ edição). Cambridge: Polity Press.

Goldberg, A. E., Downing, J. B., \& Moyer, A. M. (2012). Why parenthood, and why now? Gay mMen's motivations for pursuing parenthood. Family Relations, 61(1), 157-174. doi: 10.1111/j.1741-3729.2011.00687.x

Goldberg, A. E., Downing, J. B., \& Sauck, C. C. (2008). Perceptions of children's parental preferences in lesbian two-mother households. Journal of Marriage and Family, 70(2), 419-434. doi: 10.1111/j.1741-3737.2008.00491.x

Hamad, N. (2002). A criança adotiva e suas famílias. Rio de Janeiro: Companhia de Freud.

Hamad, N. (2010). Adoção e parentalidade: questões atuais. Porto Alegre: CMC.
Jennings, S., Mellish, L., Tasker, F., Lamb, M., \& Golombok, S. (2014). Why adoption? Gay, lesbian and heterosexual adoptive parents reproductive experiences and reasons for adoption. Adoption Quarterly, 17(3), 205-226. doi: 10.1080/10926755.2014.891549

Laville, C., \& Dione, J. (1999). A construção do saber: manual de metodologia da pesquisa em ciências humanas. Porto Alegre: Artes Médicas.

Marcondes, G. S. (2008). Refazendo famílias: trajetórias familiares de homens recasados (Tese de Doutorado). Recuperado de http://repositorio.unicamp.br/jspui/handle/REPOSIP/280645

Marvin, C., \& Miller, D. (2002). Os casais de lésbicas na entrada do século XXI. In P. Papp (Org.), D. Á. E. Burguño (Trad.), (pp. 269-294). Porto Alegre: Artmed Editora.

Matos, M. G., \& Magalhães, A. S. (2014). Tornar-se pais: sobre a expectativa de jovens adultos. Pensando Familias, 18(1), 78-91. Recuperado de http://pepsic.bvsalud.org/scielo.php?script=sci_abstract\&pi$\mathrm{d}=$ S1679-494X2014000100008\&lng=pt\&nrm=iso\&tlng=pt

Maux, A. A. B., \& Dutra, E. (2010). A adoção no Brasil: algumas reflexões. Estudos e Pesquisas em Psicologia, 10(2), 0-0. Recuperado de http://pepsic.bvsalud.org/scielo.php?script=sci_abstract\&pi$\mathrm{d}=$ S1808-42812010000200005\&lng=pt\&nrm=iso\&tIng=pt

Minuchin, S., \& Fishman, H. C. (1990). Técnicas de terapia familiar (1ㄹ ed.). Porto Alegre: Artes Médicas.

Nabinger, S. B. (2010). Adoção: o encontro de duas histórias. Santo Ângelo: FURI.

NVivo Qualitative Data Analysis Software (Version 10). (2012). Doncaster, Victoria: QSR International Pty Ltd.

Osório, L. C. (1996). Família hoje. Porto Alegre: Artes Médicas.

Otuka, L. K., Scorsolini-Comin, F., \& Santos, M. A. (2009). A configuração dos vínculos na adoção: uma atualização no contexto Latino-Americano. Revista Brasileira de Crescimento e Desenvolvimento Humano, 19(3), 475-486. Recuperado de http://pepsic.bvsalud.org/scielo.php?script=sci_abstract\&pi$\mathrm{d}=\mathrm{S} 0104-12822009000300013 \& \mathrm{lng}=\mathrm{pt} \& \mathrm{nrm}=\mathrm{iso} \& \mathrm{tlng}=\mathrm{pt}$

Paiva, L. D. (2004). Adoção: significados e possibilidades. São Paulo: Casa do Psicólogo.

Pontes, M. F., Féres-Carneiro, T., \& Magalhães, A. S. (2015). Famílias homoparentais e maternidade biológica. Revista Psicologia \& Sociedade, 27(1). Recuperado de http://www.ufrgs.br/seerpsicsoc/ ojs2/index.php/seerpsicsoc/article/view/3861

Pratta, E. M. M., \& Santos, M. A. (2007). Família e adolescência: a influência do contexto familiar no desenvolvimento psicológico de seus membros. Psicologia em Estudo, 12(2), 247-256. doi: 10.1590/ S1413-73722007000200005

Raleigh, E. (2012). Are same-sex and single adoptive parents more likely to adopt transracially? A national analysis of race, family structure, and the adoption marketplace. Sociological Perspectives, 55(3), 449-471. doi: 10.1525/sop.2012.55.3.449

Ribeiro, J. P., Silva, M. R. S., \& Cezar-Vaz, M. R. (2012). Compreendendo o exercício das competências parentais na família monoparental chefiada pelo pai. Ciência, Cuidado e Saúde, 10(3), 490-497. doi: 10.4025/cienccuidsaude.v10i3.11324

Richards, J. C., Jonathan, N., \& Kim, L. (2015). Building a circle of care in same-sex couple relationships: a socio-emotional relational approach. In C. Knudson-Martin, M. A. Wells, \& S. K. Samman (Orgs.), Springer international publishing. AFTA springer briefs in family therap. (pp. 93-105). doi: 10.1007/978-3-319-13398-0_8 
Rios, M. G., \& Gomes, I. C. (2009). Stigmatization and conjugality concerning voluntary childless couples. Psicologia em Estudo, 14(2), 311-319. doi: 10.1590/S1413-73722009000200012

Rodrigues, L., \& Hennigen, I. (2014). Visibilidades da adoção: interrogando estratégias e práticas sociais. Psicologia Argumento, 32(408), 93. doi: 10.7213/psicol.argum.32.076.AO05

Santos, C. P., Fonsêca, M. C. S. M., Fonsêca, C. M. S. M. S., \& Dias, C. M. S. B. (2011). Adoção por pais solteiros: desafios e peculiaridades dessa experiência. Psicologia: Teoria e Prática, 13(2), 89-102. Recuperado de http:// pepsic.bvsalud.org/scielo.php?script=sci_abstract \&pi$\mathrm{d}=$ S1516-36872011000200007\&lng=pt\&nrm=iso\&tlng=pt

Schettini, S. S. M., Amazonas, M. C. L. A., \& Dias, C. M. S. B. (2006). Famílias adotivas: identidade e diferença. Psicologia em Estudo, 11(2), 285-293 doi: 10.1590/S1413-73722006000200007

Silva, P. S. (2015). Os processos de habilitação para adoção do ponto de vista de técnicos judiciários do Rio Grande do Sul (Dissertação de mestrado). Recuperado de http://hdl.handle.net/10183/156749

Souza, A. B. L., Beleza, M. C. M., \& Andrade, R. F. C. (2013). Novos arranjos familiares e os desafios ao direito de família: uma leitura a partir do Tribunal de Justiça do Amazonas. PRACS: Revista Eletrônica de Humanidades do Curso de Ciências Sociais da
UNIFAP, O(5), 105-119. Recuperado de http://periodicos.unifap.br/ index.php/pracs/article/view/577

Stavrova, O., \& Fetchenhauer, D. (2015). Single parents, unhappy parents? Parenthood, partnership, and the cultural normative context. Journal of Cross-Cultural Psychology, 46(1), 134-149. doi: $10.1177 / 0022022114551160$

Uziel, A. P. (2000). "Tal pai, tal filho" em tempos de pluriparentalidade: expressão fora do lugar? In Associação Nacional de PósGraduação e Pesquisa em Ciências Sociais (Org.), XXIV Encontro Anual da ANPOCS, GT Família e Sociedade. Petrópolis, Rio de Janeiro.

Wagner, A., \& Levandowski, D. C. (2008). Sentir-se bem em família: um desafio frente à diversidade. Textos \& Contextos, 7(1), 88-97. Recuperado de http://revistaseletronicas.pucrs.br/ojs/index.php/ fass/article/view/3940

Zambrano, E. (2006). Parentalidades “impensáveis": pais/mães homossexuais, travestis e transexuais. Horizontes Antropológicos, 12(26), 123-147. doi: 10.1590/S0104-71832006000200006

Zanetti, S. S., Oliveira, R. R., \& Gomes, I. C. (2013). Concepções diferenciadas de família no processo de avaliação de pretendentes à adoção. Semina: Ciências Sociais e Humanas, 34(1), 17-30. doi: 10.5433/1679-0383.2013v34n1p17

1. Os trechos em itálico referem-se às falas dos participantes, sendo identificados apenas pelo número. Eles não foram apontados conforme a profissão para evitar a exposição da identidade dos mesmos.

Patricia Santos da Silva, Mestre em Psicologia pela Universidade Federal do Rio Grande do Sul, é Doutoranda do Programa de Pós

Graduação de Psicologia da Universidade Federal do Rio Grande do Sul. Endereço para correspondência: Rua Ramiro Barcelos, 2600 sala 112 CEP 90.035-003 Porto Alegre, RS. Telefone: 51996596526. E-mail: patis.psico@gmail.com

Eduarda Xavier de Lima e Silva, Graduanda de Psicologia pela Universidade Federal do Rio Grande do Sul, é Bolsista de Iniciação Científica Psicologia Universidade Federal do Rio Grande do Sul. E-mail: eduarda_xavierls@hotmail.com

Rita de Cássia Sobreira Lopes, PhD em Psicologia pela Universidade de Londres, é Professora Titular do Instituto de Psicologia da Universidade Federal do Rio Grande do Sul. E-mail: sobreiralopes@portoweb.com.br

Giana Bitencourt Frizzo, Doutora e pós-doutora em Psicologia pela Universidade Federal do Rio Grande do Sul, é Professora Associada no Instituto de Psicologia da Universidade Federal do Rio Grande do Sul. E-mail: gifrizzo@gmail.com 